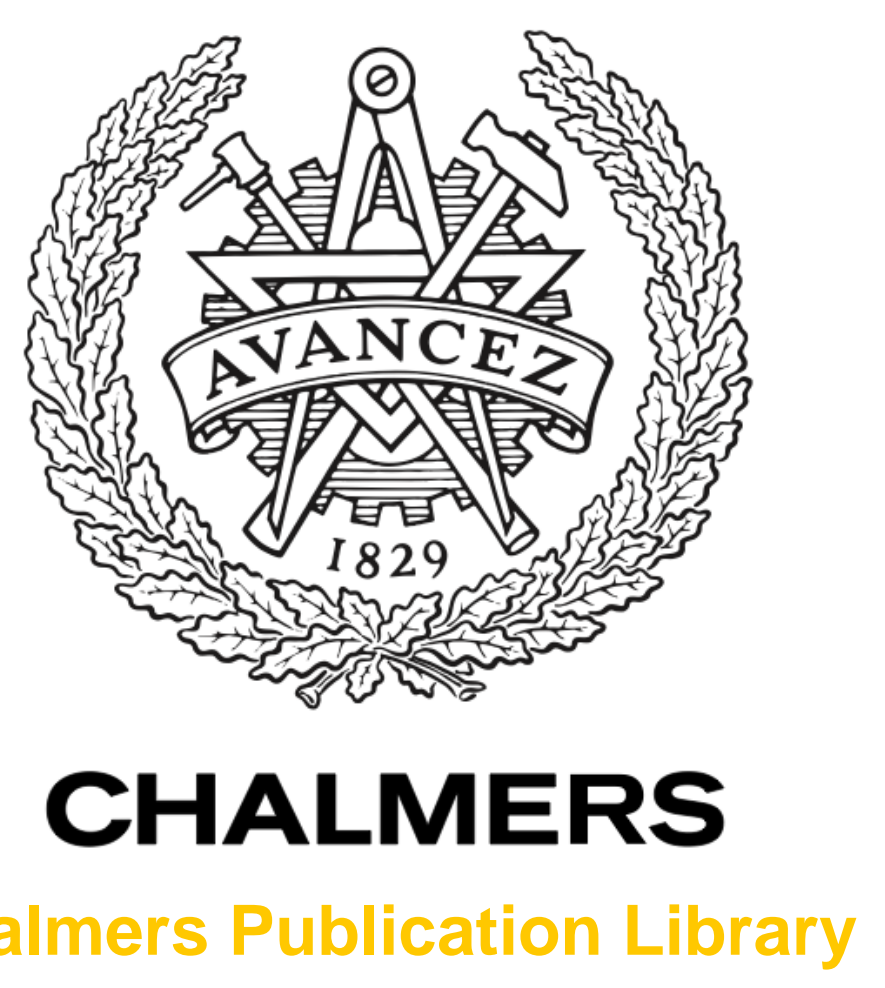

Challmers Publication Library

\title{
Intercalibration and Validation of Observations From ATMS and SAPHIR Microwave Sounders
}

This document has been downloaded from Chalmers Publication Library $(\mathrm{CPL})$. It is the author's version of a work that was accepted for publication in:

leee Transactions on Geoscience and Remote Sensing (ISSN: 0196-2892)

Citation for the published paper:

Moradi, I. ; Ferraro, R. ; Eriksson, P. et al. (2015) "Intercalibration and Validation of Observations From ATMS and SAPHIR Microwave Sounders". Ieee Transactions on Geoscience and Remote Sensing, vol. 53(11), pp. 5915-5925.

http://dx.doi.org/10.1109/tgrs.2015.2427165

Downloaded from: http://publications.lib.chalmers.se/publication/222254

Notice: Changes introduced as a result of publishing processes such as copy-editing and formatting may not be reflected in this document. For a definitive version of this work, please refer to the published source. Please note that access to the published version might require a subscription. 


\title{
Inter-calibration and validation of observations from ATMS and SAPHIR microwave sounders
}

\author{
Isaac Moradi, Ralph Ferraro, Patrick Eriksson, Fuzhong Weng
}

\begin{abstract}
This study evaluates the radiometric accuracy of observations from Advanced Technology Microwave Sounder (ATMS) onboard Suomi National Polar-orbiting Partnership (S-NPP) and Sondeur Atmospherique du Profil d' Humidité Intropicale par Radiométrie (SAPHIR) onboard Megha-Tropiques (M-T) through inter-calibration as well as validation versus in-situ radiosonde and Global Positioning System Radio Occultation (GPS-RO) observations. SAPHIR and ATMS water vapor channels operate at slightly different frequencies. We calculated the bias due to radiometric errors as the difference between observed and simulated differences between the two instruments. This difference, often referred to as double difference, ranges between $0.3 \mathrm{~K}$ to $0.7 \mathrm{~K}$ which shows a good consistency between the instruments. We used a radiative transfer model to simulate the satellite brightness temperatures $(\mathrm{Tb})$ using radiosonde and GPS-RO profiles, and then compared simulated and observed Tb's. The difference between radiosonde and ATMS Tb's for the middle and upper tropospheric temperature sounding channels was less than 0.5 $\mathrm{K}$ at most stations, but the difference between radiosonde and ATMS/SAPHIR Tb's for water vapor channels was between $0.5 \mathrm{~K}$ and $2.0 \mathrm{~K}$. The larger bias for the water vapor channels is mainly due to several errors in radiosonde humidity observations. The mean difference between ATMS observations and the Tb's simulated using GPS-RO profiles was $0.2,0.3,0.4,0.2$, and $-0.2 \mathrm{~K}$ for channels $10-14$, respectively, and the uncertainty increases from 0.02 $\mathrm{K}$ for channel 10 to $0.07 \mathrm{~K}$ for channel 14 .
\end{abstract}

Index Terms

microwave, remote sensing, water vapor, climate change, hydrology, JPSS

\section{INTRODUCTION}

Microwave (MW) satellite measurements and derived products play a very important role in weather forecasting, data assimilation, and also in climate monitoring and assessment. These data are widely used to derive information about key climate variables such as precipitation as well as atmospheric water vapor and temperature [1]-[5]. MW data are routinely measured by a series of microwave instruments onboard polar-orbiting and low-inclination

I. Moradi is with Cooperative Institute for Climate and Satellites, Earth System Science Interdisciplinary Center (ESSIC), University of Maryland, and the NOAA Joint Center for Satellite Data Assimilation, College Park, MD 20740, USA. e-mail: Isaac.Moradi@noaa.gov.

R. Ferraro, and F. Weng are with the Center for Satellite Applications and Research, National Environmental Satellite, Data, and Information Service, National Oceanic and Atmospheric Administration (NOAA), College Park, MD 20740, USA.

Patrick Eriksson is with Department of Earth and Space Sciences, Chalmers University of Technology, Gothenburg, SE-41296, Sweden. 
satellites, e.g., Advanced Microwave Sounding Unit-A (AMSU-A), AMSU-B, and Microwave Humidity Sounder (MHS) onboard NOAA and MetOp satellites, Advanced Technology Microwave Sounder (ATMS) onboard Suomi National Polar-orbiting Partnership (S-NPP) and future Joint Polar Satellite System (JPSS) satellites, and Sondeur Atmospherique du Profil d' Humidité Intropicale par Radiométrie (SAPHIR) onboard Megha-Tropiques (M-T).

Spaceborne MW measurements, like any other physical measurements, are subject to errors and uncertainties that can be classified into radiometric and geometric errors [6]. Radiometric errors, the focus of this paper, are caused by several sources, including drift in sensor calibration, imperfect antenna and local electronics, Radio Frequency Interference (RFI), reflector emissivity, uncertainty in the warm and cold (space-view) load temperatures, and nonlinearity in the calibration. Due to the lack of reference measurements for validating MW observations, alternative methods are used to quantify the radiometric errors in MW measurements. These methods include validation using airborne observations [7]; inter-calibration with similar spaceborne instruments [8]-[10]; inter-comparison with forward calculations using a radiative transfer model and atmospheric state variables from radiosonde [3], NWP model fields, or Global Positioning System Radio Occultation (GPS-RO) [11].

Inter-comparing observations from similar spaceborne instruments is one of the methods that has been extensively used to identify relative differences between the instruments and allow for proper usage of their measurements and derived products especially for developing long-term records for climate applications [8], [9]. In this case, one of the instruments that is stable over time in terms of its performance and minimal orbital drift is chosen as the reference and other (target) instruments are inter-calibrated with respect to the reference instrument. Inter-calibration requires that both target and reference instruments observe the same location as close in time as possible. Inter-satellite differences are normally scene dependent, thus the coincident observations should cover a wide range of atmospheric and surface conditions. However, most of the collocations from sun-synchronous polar-orbiting satellites occur at high latitudes, where the observed brightness temperatures ( $\mathrm{Tb}$ 's) are normally low. Therefore, inter-calibration of MW instruments onboard polar-orbiting satellites has always been challenging. The low-inclination non sun-synchronous satellites, e.g., the M-T satellite, yield numerous collocations with sun-synchronous polar orbiting satellites, e.g., the S-NPP satellite, in the tropical region and offer more opportunities for direct time and space collocations. Nevertheless, inter-comparing similar instruments only reveals the relative differences between the instruments and cannot be used to identify the absolute errors in the measurements. It is likely that both reference and target instruments have common errors, especially if both instruments are fabricated by the same manufacturer. However, this seems to be unlikely in the current comparison, as ATMS and SAPHIR instruments were designed and manufactured by different companies. Indeed, it is still possible that different manufacturers use the same components, e.g., amplifiers, oscillators, filters, made by a common party. Other methods that can be employed to validate the microwave satellite observations include inter-comparing satellite observations with brightness temperatures simulated using radiosonde and GPS-RO profiles and a radiative transfer model. However, both radiosonde and GPS-RO data, as well as radiative transfer calculations, are subject to errors and uncertainties that affect the reliability of the results.

ATMS and SAPHIR are microwave sounding instruments flying onboard S-NPP and M-T satellites, respectively. ATMS provides information about both atmospheric water vapor and temperature [12], [13], but SAPHIR is only 
equipped with water vapor channels operating near the water absorption line at $183 \mathrm{GHz}$ and provides information about the distribution of tropospheric water vapor in the tropical region [14]. Although, these instruments are well calibrated and tested before launch, they require extensive post-launch assessment and validation due to possible drift in calibration. This paper focuses on inter-comparing observations from similar water vapor channels on SAPHIR and ATMS instruments, validating SAPHIR and ATMS water vapor, as well as ATMS mid-upper tropospheric temperature sounding channels using radiosonde data, and validating ATMS upper tropospheric and stratospheric temperature sounding channels using GPS-RO profiles.

The reminder of this paper is organized as follows. Section II introduces data and satellite instruments, Section III discusses the methodology and collocation criteria, Section IV present the results and findings of this study, and Section V summarizes the study.

\section{DAta AND InStRuments}

\section{A. ATMS and SAPHIR Instruments}

ATMS is a cross-track microwave sounder with 22 channels operating at microwave frequencies from $23.8 \mathrm{GHz}$ to $190.31 \mathrm{GHz}$. ATMS is currently flying on the S-NPP satellite and is planned to fly on the United States next generation polar-orbiting operational environmental satellite system named Joint Polar Satellite System (JPSS). S-NPP, launched in October 2011, is in a sun-synchronous orbit, an altitude of $824 \mathrm{~km}$ and an inclination of 97.1 $1^{\circ}$, yielding an orbital period of 101 minutes, with the ascending equatorial crossing time at 01:30 p.m. [15]. The ATMS characteristics, including frequency, band width, beam-width, and the noise equivalent temperature difference $(\mathrm{NE} \Delta \mathrm{T})$, are reported in Table I.

Weighting functions, that show the sensitivity of the ATMS channels to different altitudes of the atmosphere, are shown in Figure 1. In this study, we used ATMS Sensor Data Records (SDR) which are corrected for the antenna pattern and converted to $\mathrm{Tb}$ in Kelvin [12], [16], [17].

M-T, launched in Nov 2011, is a low-inclination satellite with an altitude of $865 \mathrm{~km}$ and an inclination of $19.98^{\circ}$, yielding an orbital period of 101 minutes. This means that the satellite only visits the tropical band between $30 \mathrm{~S}$ and $30 \mathrm{~N}$. There are primarily two MW instruments onboard M-T: MADRAS (Microwave Analysis and Detection of Rain and Atmospheric Systems), and SAPHIR. The MADRAS instrument, whose primary purpose was to measure atmospheric temperature, surface properties, and precipitation, experienced several malfunctions and is now not operating, so the SAPHIR is currently the only operational microwave instrument onboard the M-T satellite. The characteristics of the channels of SAPHIR are shown in Table II. All SAPHIR channels have horizontal polarization, the swath width is $1700 \mathrm{~km}$, and the resolution is $10 \mathrm{~km}$ at nadir for all the channels. As is shown, SAPHIR and ATMS channels operate at slightly different frequencies and SAPHIR also has a few additional water vapor channels. Weighting functions for SAPHIR channels are also shown in Figure 1. We used SAPHIR L1A data that are processed by the Centre National d'Etudes Spatiales (CNES). SAPHIR data are not corrected for the antenna pattern, but because of the high beam efficiency, the effect of antenna pattern correction is negligible for the water vapor channels [17]. 


\section{B. GPS-RO Observations}

GPS-RO observations signifies the radio signals transmitted by the GPS satellites measured by a receiver on a Low Earth Orbiting (LEO) satellite. GPS-RO measurements represent the atmosphere between the GPS satellite and the LEO satellite and a series of such measurements are organized in one profile. The primary measurement is the delay (phase) of the signal due to refraction by the atmosphere between the GPS and LEO during the occultation. However, these raw measurements cannot be directly used in many applications. Therefore the time delay is converted to bending angle of the signal. The bending angle then is transformed into refractivity using the Abel transformation. Finally, the refractivities are transformed into atmospheric products of temperature, humidity and pressure using a-priori profiles as well as the hydrostatic equilibrium concept. The refractivity $(\mathrm{N})$ is related to atmospheric pressure (P, mbar), temperature ( $T$, Kelvin), and humidity as follows:

$$
N=(n-1) \times 10^{6}=77.6 \frac{P}{T}+3.73 \times 10^{5} \frac{P_{w}}{T^{2}}+4.03 \times 10^{7} \frac{n_{e}}{f^{2}}+1.4 W
$$

where, $P_{w}$ is the partial pressure of water vapor in mbar, $n_{e}$ is electron number density, $\mathrm{f}$ is the transmission frequency in $\mathrm{Hz}$, and $\mathrm{W}$ is the liquid water content in grams per cubic meter. These terms are referred to as dry, wet, ionospheric, and scattering terms [18]. The dry term is the most significant term from the upper troposphere to upper stratosphere.

The raw measurements of time delay are very accurate and stable from the middle troposphere to lower stratosphere, extending roughly from $5 \mathrm{~km}$ to $25 \mathrm{~km}$ [19], [20]. However, outside this range the GPS-RO data are affected by several errors including super-refraction in the lower troposphere [21], [22], residual ionospheric effect, and the Abel high-altitude initialization above $25 \mathrm{~km}$ [19], [23]. In this study, we used GPS-RO data from the Constellation Observing System for Meteorology, Ionosphere and Climate (COSMIC) which are available from 6 LEO satellites since 2006. We used GPS-RO wet profiles available from the University Corporation for Atmospheric Research (UCAR).

\section{Radiosonde Data}

The Atmospheric Radiation Measurement (ARM) Climate Research Facility is a global change research program supported by the United States Department of Energy since 1989. In this study we used radiosonde data from the following ARM stations: the Tropical Western Pacific stations (TWP-C1, -C2, and -C3) located in Manus Island (Papua New Guinea), Nauru Island (the Republic of Nauru), and Darwin (Australia), respectively, and Southern Great Plains (SGP-C1) located in Lamont (Oklahoma, USA) [24], [25]. The ARM stations are equipped with Vaisala RS92 sensors for measuring relative humidity. While RS92 is one of the most reliable sensors, several errors are involved in the measurements including daytime radiation dry bias and contamination errors. Because of large magnitude of the daytime radiation bias [26], [27], we only used nighttime data that normally extend from the ground to about $20 \mathrm{~km}$. 


\section{INTER-COMPARISON METHOD}

This study includes three steps: (1) inter-comparing similar water vapor channels on ATMS and SAPHIR, (2) evaluating observations from ATMS and SAPHIR water vapor channels as well as ATMS middle and upper tropospheric temperature sounding channels versus radiosonde data, (3) evaluating observations from ATMS upper tropospheric and stratospheric temperature sounding channels versus GPS-RO profiles. The last two steps are conducted by simulating ATMS and SAPHIR Tb's using the Community Radiative Transfer Model (CRTM) [28].

\section{A. Collocation Criteria}

Inter-calibrating satellite observations from two different platforms, and likewise evaluating satellite observations using in-situ radiosonde and GPS-RO profiles, require careful matching between the observations. In the case of collocating ATMS and SAPHIR observations, the two instruments have different characteristics and geometries, as was previously described. S-NPP and M-T produce a lot of coincident observations because the overpass times for S-NPP and M-T are not synchronized, but, because of difference in the geometry, most of the collocations can not be used for inter-comparison. Therefore, we limited the collocations to nadir observations to ensure that both satellites observe the same target with the same geometry. Since true nadir observations do not exist for either of the instruments, we only used the sub-nadir beam positions for the inter-comparison. Other collocation criteria were a time difference of less than $1 \mathrm{hr}$, and spatial distance of less than $50 \mathrm{~km}$. However, as it is explained later, these thresholds are not very critical in our study, since SAPHIR and ATMS collocations occur in tropical region where the diurnal variation of satellite brightness temperatures is small.

In the case of collocating satellite and radiosonde or GPS-RO profiles, it is required to take into account that satellite data are area averaged, while radiosonde data are point measurements and GPS-RO data are limb-sounding measurements. Both radiosonde and GPS-RO profiles drift with altitude. The drift in radiosonde profiles is estimated to be around $50 \mathrm{~km}$ but highly depends on the wind speed and balloon burst altitude. Drift in GPS profiles depends on the geometry of GPS and LEO orbits and is discussed in Section IV.

Because of the drift in the profiles, it is not possible to collocate sonde and GPS profiles with an individual satellite footprint, therefore we collocated each profile with all the satellite footprints within a target area with a radius of $50 \mathrm{~km}$. It should be noted that in the case of collocating satellite observations with radiosonde or GPS-RO profiles, restricting the collocations to nadir-only satellite observations will greatly reduce the number of collocations. Therefore, we should take into account satellite observations from all the beam positions. In this case, radiative transfer models can simulate $\mathrm{Tb}$ 's for the corresponding earth incidence angles.

In addition, satellite observations are subject to cloud effects, even at MW frequencies, while the Tb's simulated using a radiative transfer model are simulated for clear sky conditions. Thus, it is required to filter out the cloud contaminated observations before conducting the collocation. Due to the natural lapse rate in temperature, the Tb's for the channels sensitive to higher altitudes of the atmosphere are lower than the Tb's for those channels sensitive to the lower altitudes. In the presence of optically thick clouds, the Tb's for the upper channels become either very close or even greater than Tb's for the lower channels [29]-[31]. We used Ice Water Path (IWP) data developed 
from ground cloud radar and satellite microwave measurements [32] to develop the cloud filters for ATMS and SAPHIR. The cloud screening method developed here is very similar to those reported for AMSU, e.g. [29], [31], but we examined the thresholds independently. Generally, the difference between Tb's for a channel sensitive to lower troposphere and a channel sensitive to upper troposphere is utilized as the cloud filter. In this study, $183 \pm 1$ (Tb1) and 183 \pm 7 (Tb7) are employed as upper and lower tropospheric channels, respectively. Figure 2 shows the difference between $\mathrm{Tb} 1$ and $\mathrm{Tb} 7, \Delta T b=T b 1-T b 7$, as a function of IWP values. As is shown, the observations are almost independent of IWP as long as $\Delta T b$ is less than $-15 \mathrm{~K}$, then the $\Delta T b$ increases with IWP. Figure 2 also shows the relation between Tb1 and IWP. Tb1 is normally larger than $240 \mathrm{~K}$ under clear sky conditions or thin clouds then decreases with IWP. We used a threshold of $240 \mathrm{~K}$ for Tb1 so that the pixel is determined to be cloud-free if $\Delta T b<-15 \mathrm{~K}$ and $\mathrm{Tb} 1>240 \mathrm{~K}$. Both thresholds were determined using RT calculations. Some of the observations that are associated with very low IWP are also screened out by the Tb1 filter. It is possible to choose a lower threshold for $\mathrm{Tb} 1$ to avoid this, but we decided to use the threshold determined by the RT

calculations. The cloud-free observations for SAPHIR can be determined using similar channels, i.e. $183 \pm 1.1$ for Tb1 and $183 \pm 6.8$ for Tb7. The thresholds are also valid for the SAPHIR channels. MW temperature sounding channels operate at a frequency of $50 \mathrm{GHz}$ to $60 \mathrm{GHz}$ (a wavelength $(\lambda)$ of $6 \mathrm{~mm}$ to $5 \mathrm{~mm}$ ). Significant scattering occurs only if particles have a size that is of the same order as the wavelength. Thus the temperature sounding channels that operate at low frequencies, with a very large wavelength, are not as sensitive as water vapor channels to clouds, but primarily to larger hydrometers like snow and hail [33]. In addition, these channels peak at altitudes higher than where precipitating clouds form, thus the impact of precipitating clouds on these channels is minimal. Therefore, we did not apply any cloud filter to data from temperature sounding channels. In summary, collocating in-situ radiosonde and GPS-RO data with satellite measurements require four criteria: the time difference between the measurements, the spatial distance between the measurements, the size of the target area, and cloud screening for the satellite data from water vapor channels.

\section{Results}

In this section, we first discuss the results for inter-comparing SAPHIR and ATMS water vapor channels, then compare SAPHIR and ATMS water vapor channels as well as ATMS mid-upper tropospheric temperature sounding channels versus ARM radiosonde data. Finally we validate ATMS upper tropospheric and stratospheric temperature sounding channels using GPS-RO data. We used data for the period of January 2012 to October 2013.

\section{A. Inter-comparing SAPHIR and ATMS observations}

We first collocated ATMS and SAPHIR observations in clear sky conditions, with a time threshold of $1 \mathrm{hr}$ and a spatial threshold of $50 \mathrm{~km}$. Figure 3 shows the comparison between collocated ATMS and SAPHIR observations. The frequencies of ATMS and SAPHIR channels as well as the statistics for the comparison are indicated on the plots. As is shown, the mean difference (bias) between the ATMS and SAPHIR observations is -0.7, -1.6, -1.2, and $0.4 \mathrm{~K}$ for the lower to upper channels, respectively. The statistical uncertainty of the bias is negligible in 
all cases. The correlation coefficients between SAPHIR and ATMS observations are greater than 0.98 for all the channels. The slope of the fitted line ranges between 0.98 and 1.0 which is very close to unity. Because of the frequency difference between the SAPHIR and ATMS channels, the weighting functions of the similar channels peak at slightly different altitudes which introduces a systematic difference between the observations of the two instruments. Therefore, the difference between ATMS and SAPHIR observations $\left(D_{O}\right)$ is due to both radiometric errors and frequency mismatch. The difference due to frequency mismatch should not be taken as a bias in the observations. This difference was estimated by simulating ATMS and SAPHIR Tb's using a subset of randomly selected ARM radiosonde profiles and the CRTM model, then subtracting the simulated Tb's from each other $\left(D_{S}\right)$. Finally, the difference between $D_{O}$ and $D_{S}$, which can be counted as a double difference shows the bias due to radiometric errors. The aforementioned statistics, i.e., $D_{O}, D_{S}$, and double difference, are reported in Table III. As is shown, the double difference ranges from $-0.3 \mathrm{~K}$ to $-0.7 \mathrm{~K}$ for different channels which shows a very good agreement between the two instruments.

The double differences (SAPHIR minus ATMS) are negative for all the channels, meaning that SAPHIR measurements are systematically lower than ATMS measurements. However, these systematic differences should not be attributed to a larger radiometric error in one of the instruments unless can be independently justified. We employed a third instrument, the MHS instrument onboard NOAA-19, to further investigate this systematic difference. The double difference between SAPHIR and MHS measurements, similar to the double differences for SAPHIR and ATMS measurements, are shown in Table III. MHS has three water vapor channels operating at $183 \pm 1,183 \pm 3$, and $183 \pm 7 \mathrm{GHz}$, but it does not have any channel at $183 \pm 4.5 \mathrm{GHZ}$. Therefore, the statistics are not shown for that specific channel. The results show that only SAPHIR S3 has a negative bias relative to MHS. Although, the difference between SAPHIR S2 and the corresponding channel on MHS is negative, the difference is small and negligible. However, SAPHIR S5 has a positive bias $(0.2 \mathrm{~K})$ relative to the corresponding channel on MHS. The difference between double differences of SAPHIR relative to ATMS and MHS instruments, i.e., [SAPHIR - ATMS] - [SAPHIR - MHS], can be counted as the difference between MHS and ATMS. As shown in Table III, ATMS Channels 18 and 22 have a cold bias relative to corresponding channels on MHS, but ATMS Channel 20 has a warm bias relative to MHS. The results, with mixed positive and negative double differences, show the sensitivity of the inter-calibration to the reference instrument. In addition, employing SAPHIR measurements to calculate the differences between the MHS and ATMS instruments, indicates a great application of double differences using measurements from low-inclination satellites to transfer calibrations among the polar orbiting satellites.

Figure 3 also shows the mean difference between ATMS and SAPHIR Tb's as a function of ATMS Tb, temporal difference and spatial distance between the collocations. The slope of the fitted line between the inter-satellite differences and ATMS Tb's can be up to 0.02, which means that the scene dependency of the differences between the two instruments can be up to about $2 \mathrm{~K}$ per $100 \mathrm{~K}$ change in the scene temperatures. This indicates that the scene dependency of the inter-calibration coefficients is important and should be taken into account when intercalibrating microwave instruments. However, the mean difference does not show any significant relation with temporal difference and spatial distance. For instance, a $50 \mathrm{~km}$ spatial distance would only introduce less than $0.05 \mathrm{~K}$ error, since the 
slope of the fitted line between distance and the differences is up to $0.001 \mathrm{~K} \mathrm{~km}^{-1}$, and a one hour time difference would only introduce less than $0.03 \mathrm{~K}$ bias because the slope of the fitted is $0.03 \mathrm{~K} \mathrm{hr}^{-1}$ for the time difference. However, the standard deviation of the difference between ATMS and SAPHIR significantly increases with spatial distance, as might be expected, ranging from $2 \mathrm{~K}$ to $8 \mathrm{~K}$ over distances of $50 \mathrm{~km}$ to $300 \mathrm{~km}$. The sensitivity to changes in time are not very critical, with only a slight increase in the standard deviation. It should be noted that these results are only valid in tropical region due to negligible diurnal variation of temperature and humidity and the results should not be extended to the regions outside tropical region.

Figure 4 shows the time series of the weakly moving averages of differences between SAPHIR and ATMS measurements. The differences between the two instruments are very stable and only show some small fluctuations. The time series is almost for two years, thus not enough for evaluating the seasonal dependency or trends in the differences between the two instruments. Seasonal dependency can be introduced by either seasonal change in the diurnal variation of Tb's or seasonal variation in the regime of the convective clouds since those clouds has a significant effect on ATMS water vapor channels. However, in the tropical region the diurnal variation is very small and may only slightly change with season. We also used a small time threshold that will eliminate the impact of a small diurnal variation on the inter-comparison results. In addition, we screened out the cloud contaminated observations from the analysis. Thus, the inter-comparison results are not expected to have any seasonal dependency even a longer period of data is used for inter-comparison.

\section{B. Comparison with radiosonde data}

Figure 5 shows the bias for both SAPHIR and ATMS observations versus simulated Tb's using CRTM and ARM radiosonde profiles. The figure shows the bias with respect to Tb's simulated using both land and ocean emissivity. Since MW surface emissivity, especially over land, is not well known for these frequency ranges, this is particularly useful to see whether the bias is affected by the surface emissivity. Figure 5 only shows the ATMS temperature sounding channels that are sensitive to mid-upper troposphere and also the water vapor channels for both instruments. The bias for the lower tropospheric and window channels of ATMS is largely influenced by the surface emissivity. Besides, radiosonde profiles only reach up to about $20 \mathrm{hPa}$, so the simulated $\mathrm{Tb}$ 's for stratospheric channels, that are sensitive to altitudes outside the range of sonde profiles, are not reliable and show very large biases. Therefore, we excluded the channels whose weighting functions peak either in lower troposphere near the surface or above the tropopause. Figure 5 shows that for the channels that are sensitive to middle to upper troposphere, the difference between the land and ocean biases is very small indicating that the statistics are not affected by the surface emissivity. The TWP stations are located in tropical region where total precipitable water is very high, thus the weighting functions of the water vapor channels peak at high altitudes and the measurements are almost insensitive of the surface. However, the SGP station that is located at mid-latitudes shows a large surface contribution for ATMS channels 17 and 18, that can be seen in the differences between land and ocean biases. TWP-C3 shows very large biases for SAPHIR Channel 2 and ATMS Channels 21 and 22. This large bias is not related to the surface contribution, because the differences between the land and ocean biases are very small. The 
bias is unlikely to be due to error in satellite data since other stations do not show such a large bias for those channels. Therefore, the large difference is likely to be due to error in sonde data. The results for the water vapor channels are consistent with Clain et al. [34] who reported a difference of less than $2 \mathrm{~K}$ between SAPHIR and forward calculations using radiosonde data.

Overall, the bias is smaller for the temperature sounding channels than for the water vapor channels which is mainly because the radiosonde temperature measurements have better accuracy than the sonde humidity measurements [35]-[37]. Previous studies have generally reported a dry bias for Vaisala radiosonde sensors, e.g., [3], [37]. The dry bias in sonde data is translated into larger simulated $\mathrm{Tb}$ 's for the water vapor channels. The overall result of the radiosonde dry bias is that the observed Tb's are systematically lower than simulated Tb's. The amount of the sonde dry-bias depends on many factors such as atmospheric state variables, for instance the bias is larger in dry conditions than in moist conditions, and radiosonde sensor, but it is generally estimated to be between $0.5 \mathrm{~K}$ to 1.5 K for Vaisala RS92 sensors [27], [37], [38]. If we subtract this bias from the difference between the satellite Tb's and radiosonde simulated Tb's then the remaining bias in the water vapor channels is around $1 \mathrm{~K}$ which is relatively consistent with the inter-calibration results. It should be noted that this remaining difference may be due to either radiometric error in ATMS and SAPHIR observations or sampling (temporal and spatial) mismatch between the collocations. Although, the sampling mismatch is expected to be random and cancel out when comparing radiosonde and satellite data, ARM radiosonde data used in this study are normally collected at 12:00 and 24:00 UTC, and the satellite overpass time is almost fixed in terms of local time. Therefore, the satellite will always pass over the radiosonde stations either before or after sonde launch time. In addition, it normally takes more than one hour for radiosonde to reach $20 \mathrm{~km}$ while the satellite observations are integrated in less than a second. Thus, there will be always some residual time difference between radiosonde and satellite observations. Despite all the limitations mentioned above, radiosonde data are still very valuable for validating microwave water vapor channels. In addition to the radiosonde dry-bias and sampling errors, the radiative transfer calculations are also subject to errors and uncertainty, such as error in spectroscopic databases, and line shapes, but these errors are estimated to be small [35].

\section{Comparison with GPS-RO data}

Figure 6 shows the mean difference between ATMS Tb's and Tb's simulated using GPS-RO data. The corresponding uncertainties, defined as standard deviation over the square root of the number of collocations, are shown

in Figure 7. In order to investigate the effect of temporal and spatial thresholds on the bias and uncertainty, both statistics were calculated using different thresholds. We used two different temporal (30 min and $60 \mathrm{~min}$ ) and two different spatial $(50 \mathrm{~km}$ and $100 \mathrm{~km})$ thresholds. The results are shown in Figures 6 and 7 for bias and uncertainty, respectively. Obviously, the bias does not significantly depend on the spatial and temporal thresholds. The uncertainty of the bias slightly decreases when the temporal and spatial thresholds are changed from $30 \mathrm{~min}$ to $60 \mathrm{~min}$ and from $50 \mathrm{~km}$ to $100 \mathrm{~km}$, respectively, but that is mainly due to increase in number of collocations. In addition, one of the concerns for collocating GPS-RO and satellite observations is that GPS-RO profiles drift with altitude. In order to 
investigate the impact of the drift on the statistics, we collocated satellite observations with GPS-RO location at different altitudes. The statistics calculated based on different GPS-RO location are also shown in Figures 6 and 7. The uncertainty of the bias does not depend on the GPS-RO location that is used for collocation. However, the bias for channels 13 and 14 slightly depends on the GPS-RO location when the temporal and spatial thresholds are small. This is likely to be due to limited number of collocations. Otherwise, the bias is independent of the GPS-RO location that is used for collocation. This can be explained by either a non-significant drift in the GPS-RO profiles or the homogeneity of the upper tropospheric and stratospheric temperature. Figure 8 shows the drift in GPS-RO profiles from ground to $400 \mathrm{hPa}$ as well as the drift from $400 \mathrm{hPa}$ to $100 \mathrm{hPa}$ and $10 \mathrm{hPa}$. As is shown, the drift from ground to $400 \mathrm{hPa}$ depends on the latitude and changes from more than $200 \mathrm{~km}$ in tropical region to less than $100 \mathrm{~km}$ at mid and high latitudes. Although this drift is significant, at least in tropical region, it is not important for validating satellite data using GPS-RO observations because the temperature sounding channels that are validated using GPS-RO profiles are not sensitive to this layer. In addition, as is shown in Figure 9, most of GPS-RO observation are from mid and high latitudes where the drift is not very large. The drift from $400 \mathrm{hPa}$ to $100 \mathrm{hPa}$ is mostly less than $40 \mathrm{~km}$ and does not show any changes with latitude. The drift from $400 \mathrm{hPa}$ to 10 $\mathrm{hPa}$ only slightly depends on the latitude and changes from about $80 \mathrm{~km}$ over tropical region to less than $60 \mathrm{~km}$ at mid and high latitude. The drift from $400 \mathrm{hPa}$ to $10 \mathrm{hPa}$ seems large over tropical region, but as mentioned before most of GPS-RO observations are from mid and high latitudes (Figure 9).

It is worth looking closer at the statistics that are computed using a temporal threshold of $60 \mathrm{~min}$ and a spatial threshold of $100 \mathrm{~km}$. The bias is about $0.2,0.3,0.4,0.2$ and $-0.2 \mathrm{~K}$ for channels 10 to 14 , respectively. The uncertainty of the bias generally increases from about $0.02 \mathrm{~K}$ for channel 10 to about $0.07 \mathrm{~K}$ for channel 14 . The increase in uncertainty is related to higher NE $\Delta \mathrm{T}$ for the upper channels of ATMS, see Table I. In addition, the GPS-RO profiles only extend up to around $30 \mathrm{~km}$ and the accuracy of the observations above $25 \mathrm{~km}$ is also questionable, which may introduce a random error in the simulations. We expected a larger bias for the upper channels, e.g., Channels 13 and 14, because the vertical coverage of GPS profiles does not completely cover the entire layer where those channels are sensitive to, but the bias increases from Channel 10 to 12 then decreases. This may be because the incomplete GPS-RO profiles only introduce a random error in the simulations rather than a systematic bias. Our results are consistent with Zou et al. [39] who reported less than $0.5 \mathrm{~K}$ bias for ATMS channels 10-13 compared to GPS-RO data, with the largest bias for channel 12 . They used a temporal threshold of $3 \mathrm{hr}$ and spatial threshold of $50 \mathrm{~km}$. Although, we used a smaller temporal threshold, since the statistics are not affected by the collocation thresholds, the consistency between our findings and Zou et al. [39] was expected.

Figure 10 shows scatterplots of ATMS observations versus Tb's simulated using GPS-RO observations. The left column shows the scatterplots for the collocation thresholds of $30 \mathrm{~min}$ and $50 \mathrm{~km}$ and the right column for 60 min and $100 \mathrm{~km}$. Although, both thresholds yield a very good agreement between simulated and observed Tb's, generally the standard deviation is slightly larger for the scatterplots on the right side. The rows from top to bottom are for channels 10 to 14 and as is shown the agreement (standard deviation) decreases (increases) from channel 10 to channel 14 . As was mentioned before, the increase in standard deviation is mainly related to a higher $\mathrm{NE} \Delta \mathrm{T}$ for 
the upper temperature sounding channels of ATMS. The standard deviations shown in Figure 10 are comparable to the NE $\Delta \mathrm{T}$ values reported in Table I. The results do not show any non-linearity in the ATMS calibration. The slope of the fitted line is very close to unity for all the channels and only shows a small dependency between the bias and the scene temperature. The accuracy of the GPS-RO comparison is affected by the uncertainties in radiative transfer calculations, as well as sampling error due to spatial and temporal mismatch. Although, it is very difficult to quantify the error in the Tb's simulated using GPS-RO, the overall error is expected to be small in a layer extending from about $5 \mathrm{~km}$ to about $25 \mathrm{~km}$. Therefore, GPS-RO observations provide a good opportunity for validating observations from temperature sounding channels that are sensitive to this layer, e.g., channels 10 , and 11. Although, the error increases toward the lower troposphere and upper stratosphere, nevertheless the GPS-RO comparison can be used to identify the overall accuracy of the observations from channels 9, and channels 12-14.

\section{CONClusion}

Microwave satellite data from SAPHIR and ATMS instruments are crucial to derive a variety of hydrological and meteorological products such as temperature, humidity, precipitation and cloud physical parameters. In this paper, these instruments were inter-compared and also validated using radiosonde and GPS-RO observations. The results show that the systematic differences between the observations from the two instruments are very small relative to the instrument noise and that in general, the data from the two instruments are in a very good agreement. The SAPHIR data showed a small systematic negative difference relative to the ATMS data, but further analysis using coincident data from SAPHIR and MHS showed that this systematic difference should not be interpreted as either a cold bias in the SAPHIR data or a warm bias in the ATMS data.

The ATMS temperature sounding channels sensitive to upper troposphere and stratosphere were validated using GPS-RO profiles. The mean difference between GPS-RO and ATMS observations ranges between $-0.2 \mathrm{~K}$ to $0.4 \mathrm{~K}$, and the statistical uncertainty of the bias varies from $0.02 \mathrm{~K}$ for channel 10 to about $0.07 \mathrm{~K}$ for channel 14 . The larger uncertainties for the upper level channels are introduced by a higher NE $\Delta \mathrm{T}$ for the ATMS upper channels, and also a lower accuracy for GPS-RO profiles at altitudes above $30 \mathrm{~km}$.

Radiosonde data were used to validate ATMS mid-upper tropospheric temperature sounding channels as well as ATMS and SAPHIR water vapor channels. The bias was generally larger for the water vapor channels which is related to error in the radiosonde humidity measurements.

It should be noted that the cross-calibration of satellite data can only reveal the relative difference between the two instruments. Validating satellite data using atmospheric profiles from radiosonde and GPS profiles is an alternative method to independently evaluate the accuracy of the observations. The difference between observed and simulated brightness temperatures is affected by several errors, including bias in the temperature and humidity profiles, error in radiative transfer calculations, and sampling errors due to time difference and spatial distance between the collocations. Nevertheless, GPS-RO and radiosonde data provide a good opportunity for independent evaluation of satellite observations. 


\section{ACKNOWLEDGMENT}

This study was supported by NOAA/NCDC grant\# NA09NES4400006 (Cooperative Institute for Climate and Satellites - CICS) at the University of Maryland, Earth System Science Interdisciplinary Center (ESSIC). The views, opinions, and findings contained in this report are those of the authors and should not be construed as an official National Oceanic and Atmospheric Administration or U.S. Government position, policy, or decision.

\section{REFERENCES}

[1] R. R. Ferraro, F. Weng, N. C. Grody, L. Zhao, H. Meng, C. Kongoli, P. Pellegrino, S. Qiu, and C. Dean, "NOAA operational hydrological products derived from the advanced microwave sounding unit," IEEE Trans. Geosci. Remote Sens., vol. 43, no. 5, pp. 1036-1049, 2005.

[2] S. A. Buehler, M. Kuvatov, V. O. John, M. Milz, B. J. Soden, D. L. Jackson, and J. Notholt, "An upper tropospheric humidity data set from operational satellite microwave data," J. Geophys. Res., vol. 113, no. D14, pp. n/a-n/a, 2008.

[3] I. Moradi, S. A. Buehler, V. O. John, and S. Eliasson, "Comparing upper tropospheric humidity data from microwave satellite instruments and tropical radiosondes," J. Geophys. Res., vol. 115, no. D24310, 2010.

[4] B. J. Choudhury, "Passive microwave remote sensing contribution to hydrological variables," Surveys in Geophysics, vol. 12, no. 1-3, pp. 63-84, 1991.

[5] H. Brogniez, P. Kirstetter, and L. Eymard, "Expected improvements in the atmospheric humidity profile retrieval using the Megha-Tropiques microwave payload," Q. J. R. Meteorol. Soc., vol. 139, no. 673, pp. 842-851, 2013.

[6] I. Moradi, H. Meng, and R. Ferraro, "Correcting geolocation errors for microwave instruments aboard NOAA satellites," IEEE Trans. Geosci. Remote Sens., vol. 51, pp. xx-xx, 2012, in press, doi: 10.1109/TGRS.2012.2225840.

[7] W. J. Blackwell, L. J. Bickmeier, L. G. Jairam, and R. V. Leslie, "On-orbit radiometric validation and field-of-view calibration of spaceborne microwave sounding instruments," A. Valinia, P. H. Hildebrand, and S. Uratsuka, Eds., 2008, pp. 71 540A-71 540A-12.

[8] T. Wilheit, "Comparing calibrations of similar conically scanning window-channel microwave radiometers," IEEE Trans. Geosci. Remote Sens., vol. 51, no. 3, pp. 1453-1464, 2013.

[9] M. Sapiano, W. Berg, D. McKague, and C. Kummerow, "Toward an intercalibrated fundamental climate data record of the SSM/i sensors," IEEE Trans. Geosci. Remote Sens., vol. 51, no. 3, pp. 1492-1503, 2013.

[10] V. O. John, R. P. Allan, W. Bell, S. A. Buehler, and A. Kottayil, "Assessment of intercalibration methods for satellite microwave humidity sounders," J. Geophys. Res., vol. 118, no. 10, pp. 4906-4918, 2013.

[11] W. Blackwell, R. Bishop, K. Cahoy, B. Cohen, C. Crail, L. Cucurull, P. Dave, M. DiLiberto, N. Erickson, C. Fish, S.-p. Ho, R. Leslie, A. Milstein, and I. Osaretin, "Radiometer calibration using colocated GPS radio occultation measurements," IEEE Trans. Geosci. Remote Sens., vol. 52, no. 10, pp. 6423-6433, 2014.

[12] W. Blackwell, L. Chidester, E. Kim, R. Leslie, C.-H. Lyu, and T. Mo, "NPP ATMS prelaunch performance assessment and sensor data record validation," in Geoscience and Remote Sensing Symposium (IGARSS), 2011 IEEE International, Jul. 2011, pp. 32 -34.

[13] E. Kim, C.-H. J. Lyu, K. Anderson, R. Vincent Leslie, and W. J. Blackwell, "S-NPP ATMS instrument prelaunch and on-orbit performance evaluation," J. Geophys. Res., vol. 119, no. 9, p. 2013JD020483, 2014.

[14] M. Venkat Ratnam, G. Basha, B. V. Krishna Murthy, and A. Jayaraman, "Relative humidity distribution from SAPHIR experiment on board megha-tropiques satellite mission: Comparison with global radiosonde and other satellite and reanalysis data sets," J. Geophys. Res. Atmos., vol. 118, no. 17, pp. 9622-9630, 2013.

[15] "Advanced Technology Microwave Sounder (ATMS). SDR radiometric calibration. Algorithm Theoretical Basis Document (ATBD)," N. Baker, Ed. Joint Polar Satellite System (JPSS) Ground Project, 2011.

[16] F. Weng, X. Zou, N. Sun, H. Yang, M. Tian, W. J. Blackwell, X. Wang, L. Lin, and K. Anderson, "Calibration of suomi national polar-orbiting partnership advanced technology microwave sounder," J. Geophys. Res. Atmos., vol. 118, no. 19, pp. 11,187-11,200, 2013.

[17] F. Weng, H. Yang, and X. Zou, "On convertibility from antenna to sensor brightness temperature for ATMS," IEEE Geosci. Remote Sens. Lett., vol. 10, no. 4, pp. 771-775, 2013.

[18] E. R. Kursinski, G. A. Hajj, J. T. Schofield, R. P. Linfield, and K. R. Hardy, "Observing earth's atmosphere with radio occultation measurements using the global positioning system," J. Geophys. Res., vol. 102, no. D19, pp. PP. 23,429-23,465. 
[19] C. O. Ao, A. J. Mannucci, and E. R. Kursinski, "Improving GPS radio occultation stratospheric refractivity retrievals for climate benchmarking," Geophys. Res. Lett., vol. 39, no. 12, p. L12701, 2012.

[20] S.-p. Ho, D. Hunt, A. K. Steiner, A. J. Mannucci, G. Kirchengast, H. Gleisner, S. Heise, A. v. Engeln, C. Marquardt, S. Sokolovskiy, W. Schreiner, B. Scherllin-Pirscher, C. Ao, J. Wickert, S. Syndergaard, K. B. Lauritsen, S. Leroy, E. R. Kursinski, Y.-H. Kuo, U. Foelsche, T. Schmidt, and M. Gorbunov, "Reproducibility of GPS radio occultation data for climate monitoring: Profile-to-profile inter-comparison of CHAMP climate records 2002 to 2008 from six data centers," J. Geophys. Res., vol. 117, no. D18, p. D18111, 2012.

[21] S. Sokolovskiy, "Effect of superrefraction on inversions of radio occultation signals in the lower troposphere," Radio Sci., vol. 38, no. 3, p. $1058,2003$.

[22] C. O. Ao, T. K. Meehan, G. A. Hajj, A. J. Mannucci, and G. Beyerle, "Lower troposphere refractivity bias in GPS occultation retrievals," J. Geophys. Res., vol. 108, p. 16 PP., 2003.

[23] B. Ahmad and G. L. Tyler, "Systematic errors in atmospheric profiles obtained from abelian inversion of radio occultation data: Effects of large-scale horizontal gradients," J. Geophys. Res., vol. 104, no. D4, pp. 3971-3992, 1999.

[24] G. M. Stokes and S. E. Schwartz, "The Atmospheric Radiation Measurement (ARM) program: Programmatic background and design of the cloud and radiation test bed," Bull. Amer. Met. Soc., vol. 75, no. 7, pp. 1201-1221, 1994.

[25] C. N. Long, S. A. McFarlane, A. D. Genio, P. Minnis, T. P. Ackerman, J. Mather, J. Comstock, G. G. Mace, M. Jensen, and C. Jakob, "ARM research in the equatorial western pacific: A decade and counting," Bull. Amer. Met. Soc., vol. 94, no. 5, pp. 695-708, May 2013.

[26] I. Moradi, B. Soden, R. Ferraro, P. Arkin, and H. Vmel, "Assessing the quality of humidity measurements from global operational radiosonde sensors," J. Geophys. Res., vol. 118, no. 14, pp. 8040-8053, 2013.

[27] H. Vömel, H. Selkirk, L. Miloshevich, J. Valverde-Canossa, J. Valdes, E. Kyroe, R. Kivi, W. Stolz, G. Peng, and J. A. Diaz, "Radiation dry bias of the Vaisala RS92 humidity sensor," J. Atmos. Oceanic Technol., vol. 24, no. 6, pp. 953-963, 2007.

[28] Q. Liu, P. Van Delst, Y. Chen, D. Groff, Y. Han, A. Collard, F. Weng, S.-A. Boukabara, and J. Derber, "Community radiative transfer model for radiance assimilation and applications," International Geoscience and Remote Sensing Symposium (IGARSS), pp. 3700-3703, 2012.

[29] B. Burns, X. Wu, and G. Diak, "Effects of precipitation and cloud ice on brightness temperatures in amsu moisture channels," IEEE Trans. Geosci. Remote Sens., vol. 35, no. 6, pp. 1429-1437, 1997.

[30] R. F. Adler, R. A. Mack, N. Prasad, H. Y. M. Yeh, and I. M. Hakkarinen, "Aircraft microwave observations and simulations of deep convection from 18 to 183 ghz. part i: Observations,” J. Atmos. Oceanic Technol., vol. 7, no. 3, pp. 377-391, June 1990.

[31] S. A. Buehler, M. Kuvatov, T. R. Sreerekha, V. O. John, B. Rydberg, P. Eriksson, and J. Notholt, "A cloud filtering method for microwave upper tropospheric humidity measurements," Atmos. Chem. Phys., vol. 7, no. 21, pp. 5531-5542, 2007.

[32] E.-K. Seo and G. Liu, "Retrievals of cloud ice water path by combining ground cloud radar and satellite high-frequency microwave measurements near the ARM SGP site," J. Geophys. Res., vol. 110, no. D14, p. D14203, Jul. 2005.

[33] S. D. Michele and P. Bauer, "Passive microwave radiometer channel selection basedoncloudandprecipitation information content," $Q . J . R$. Meteorol. Soc., vol. 132, no. 617, pp. 1299-1323, 2006.

[34] G. Clain, H. Brogniez, V. H. Payne, V. O. John, and M. Luo, "An assessment of SAPHIR calibration using quality tropical soundings," J. Atmos. Oceanic Technol., vol. 32, no. 1, pp. 61-78, 2015.

[35] I. Moradi, B. Soden, R. Ferraro, P. Arkin, and H. Vomel, "Assessing the quality of humidity measurements from global operational radiosonde sensors," J. Geophys. Res., vol. 118, no. 14, pp. 8040-8053, 2013.

[36] W. P. Elliott and D. J. Gaffen, "On the utility of radiosonde humidity archives for climate studies," Bull. Amer. Met. Soc., vol. 72, no. 10, pp. 1507-1520, Oct. 1991.

[37] L. M. Miloshevich, H. Vömel, D. N. Whiteman, B. M. Lesht, F. J. Schmidlin, and F. Russo, "Absolute accuracy of water vapor measurements from six operational radiosonde types launched during AWEX-G and implications for AIRS validation,” J. Geophys. Res., vol. 111, no. D9, 2006.

[38] L. M. Miloshevich, H. Vömel, D. N. Whiteman, and T. Leblanc, "Accuracy assessment and correction of Vaisala RS92 radiosonde water vapor measurements," J. Geophys. Res., vol. 114, no. D11, pp. D11 305+, June 2009.

[39] X. Zou, L. Lin, and F. Weng, "Absolute calibration of ATMS upper level temperature sounding channels using GPS RO observations," IEEE Trans. Geosci. Remote Sens., vol. 52, no. 2, pp. 1397-1406, 2014.

[40] M. T. Team, "Megha-Tropiques level 1 products definition.” Centre National d'Etudes Spatiales (CNES), 2013. 


\section{LIST OF FIGURES}

1 Temperature weighting functions for the ATMS and SAPHIR channels: (top) ATMS Channels 1-16, (bottom) ATMS (solid lines) and SAPHIR (dashed lines) water vapor channels. The legend for the bottom plot shows the passbands with respect to $183.31 \mathrm{GHz}$ (A \pm \# for ATMS and $\mathrm{S} \pm \#$ for SAPHIR) and correspond to channels 17-22 for ATMS and S6 to S1 for SAPHIR, respectively. . . . . . . . . . Relation between (top) IWP and $\Delta T b=T b 1-T b 7$, (bottom) IWP and ATMS Tb's from Channel 1. The legend shows the data that are considered either clear or cloudy by one of the filters. . . . . . . Collocated SAPHIR and ATMS observations. Rows indicate results for different channels (frequencies of both ATMS and SAPHIR channels are printed on the plots). First column shows SAPHIR Tb's versus collocated ATMS Tb's, and second to fourth columns show the difference between SAPHIR and ATMS Tb's (SAPHIR minus ATMS) as a function of ATMS Tb (scene temperature), distance between collocated SAPHIR and ATMS data, and time difference between collocated SAPHIR and ATMS data, respectively. F indicates frequency of the channels, a and b indicate the offset and slope of the fitted line, B indicates the mean difference between SAPHIR and ATMS Tb's in Kelvin, U is uncertainty of the bias in Kelvin, $\mathrm{R}$ indicates the correlation coefficient, and $\mathrm{n}$ indicates number of collocations. . . . . . . . . . . . . . . . . . . . . . . . . . Time series of the weakly moving averages of differences between SAPHIR and ATMS measurements. In the legend, $\mathrm{S}$ indicates the SAPHIR channel number and A indicates the corresponding ATMS channel. 18 Mean difference between SAPHIR/ATMS Tb's and Tb's simulated using ARM radiosonde profiles. The color-bars indicate the bias with respect to the ARM Tb's simulated using land emissivity and the black-bars indicate the bias with respect to the ARM Tb's simulated using ocean emissivity. Top panel is for SAPHIR channels where the x-labels 1-6 indicate SAPHIR S1 to S6 channels, respectively. Bottom panel is for ATMS where the x-labels show ATMS channels' number. . . . . . . . . . . . Mean difference between ATMS and GPS-RO Tb's. The time difference threshold was 30 minutes for the first row and 60 minutes for the second row. The spatial distance threshold was $50 \mathrm{~km}$ for the first column and $100 \mathrm{~km}$ for the second column. The legend indicates the altitude (in $\mathrm{hPa}$ ) where GPS coordinates were used for collocation. . . . . . . . . . . . . . . . . . . . . 20 Same as Figure 6 but for the statistical uncertainty of the mean difference between GPS-RO and ATMS. 21 Drift in GPS profiles at different altitudes: (top) drift from $400 \mathrm{hPa}$ to $10 \mathrm{hPa}$, (middle) drift from 400 $\mathrm{hPa}$ to $100 \mathrm{hPa}$, and (bottom) drift from ground to $400 \mathrm{hPa}$. The legends show the drift in $\mathrm{km}$. . . . 22

9 Spatial distribution of the number of GPS-RO profiles. . . . . . . . . . . . . . . 23

10 ATMS Tb's versus Tb's simulated using GPS-RO profiles. The rows from top to bottom are for Channels 10-14. The temporal and spatial thresholds were $50 \mathrm{~km}$ and $30 \mathrm{~min}$ for the left column and $100 \mathrm{~km}$ and $60 \mathrm{~min}$ for the right column. B is bias in K, STD is standard deviation of the differences between simulated and observed Tb's, $\mathrm{b}$ is the slope of the fitted line, $\mathrm{R}$ is correlation coefficient, and

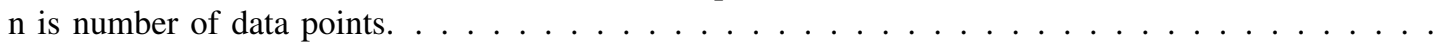




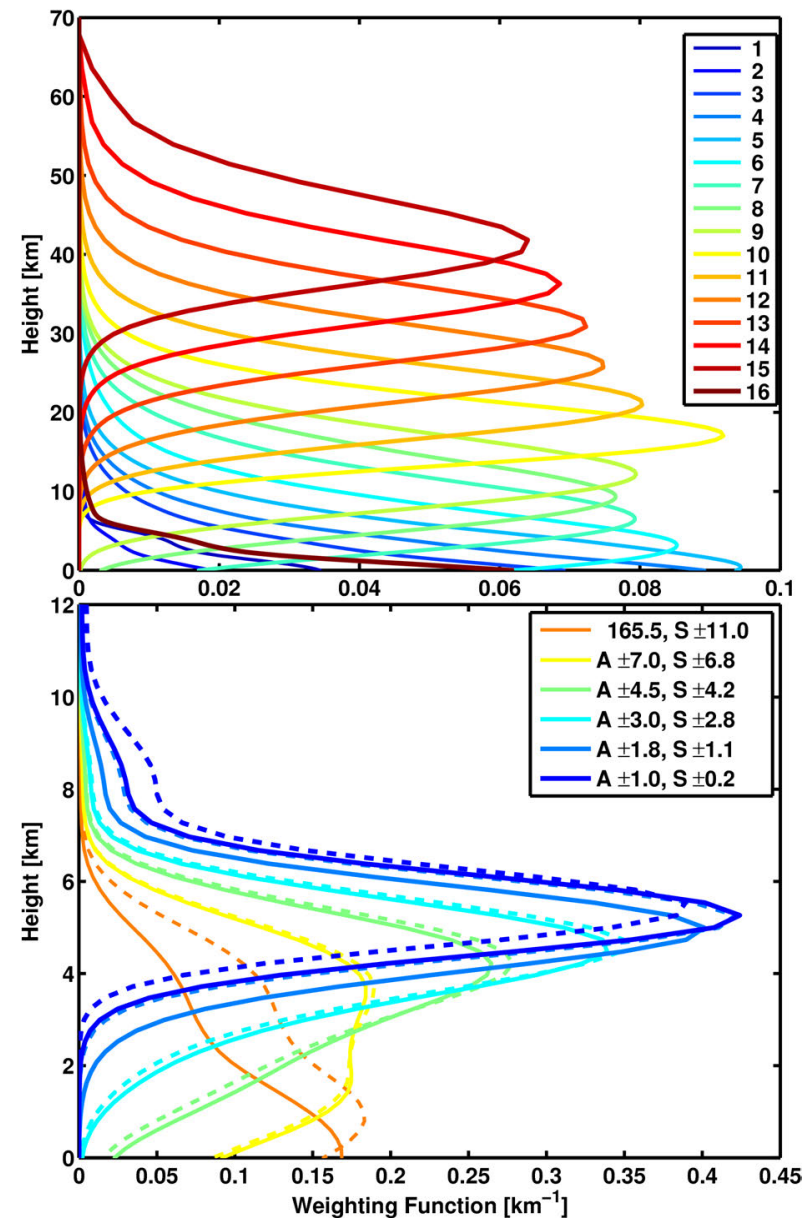

Fig. 1. Temperature weighting functions for the ATMS and SAPHIR channels: (top) ATMS Channels 1-16, (bottom) ATMS (solid lines) and SAPHIR (dashed lines) water vapor channels. The legend for the bottom plot shows the passbands with respect to $183.31 \mathrm{GHz}$ (A $\pm \#$ for ATMS and $\mathrm{S} \pm \#$ for SAPHIR) and correspond to channels 17-22 for ATMS and S6 to S1 for SAPHIR, respectively. 


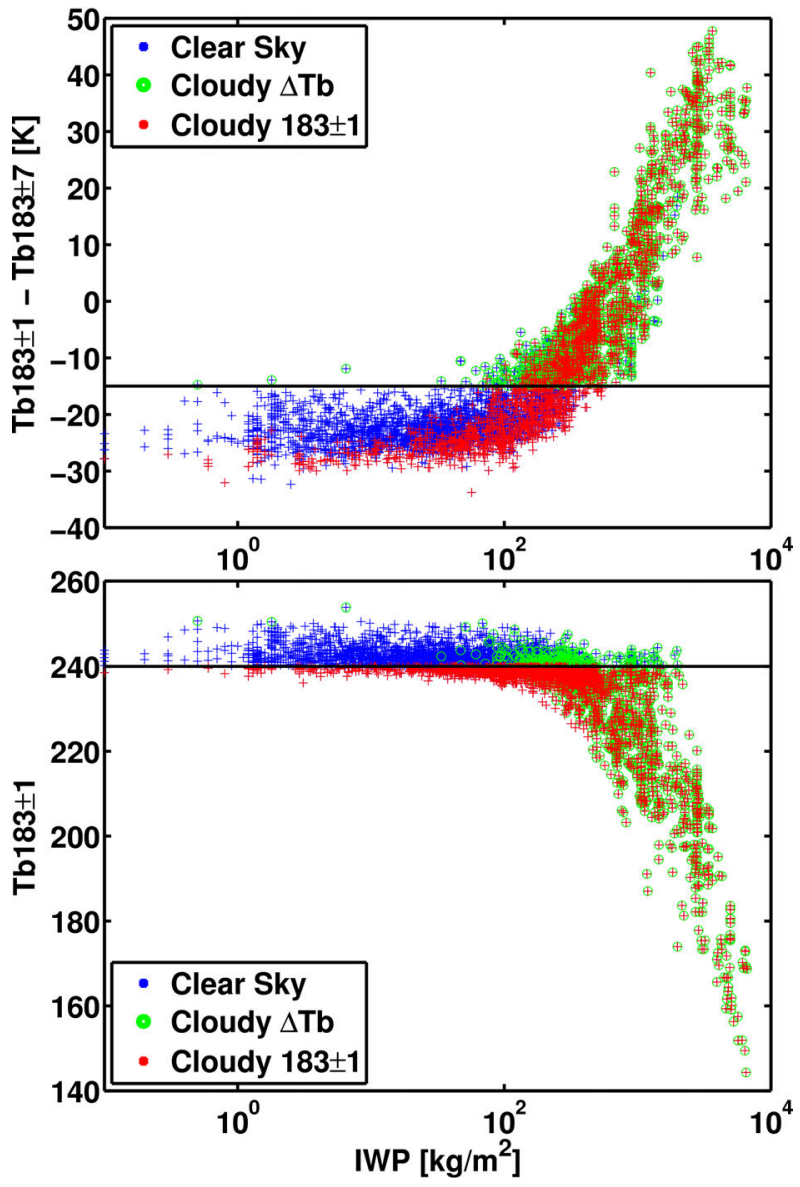

Fig. 2. Relation between (top) IWP and $\Delta T b=T b 1-T b 7$, (bottom) IWP and ATMS Tb's from Channel 1. The legend shows the data that are considered either clear or cloudy by one of the filters. 

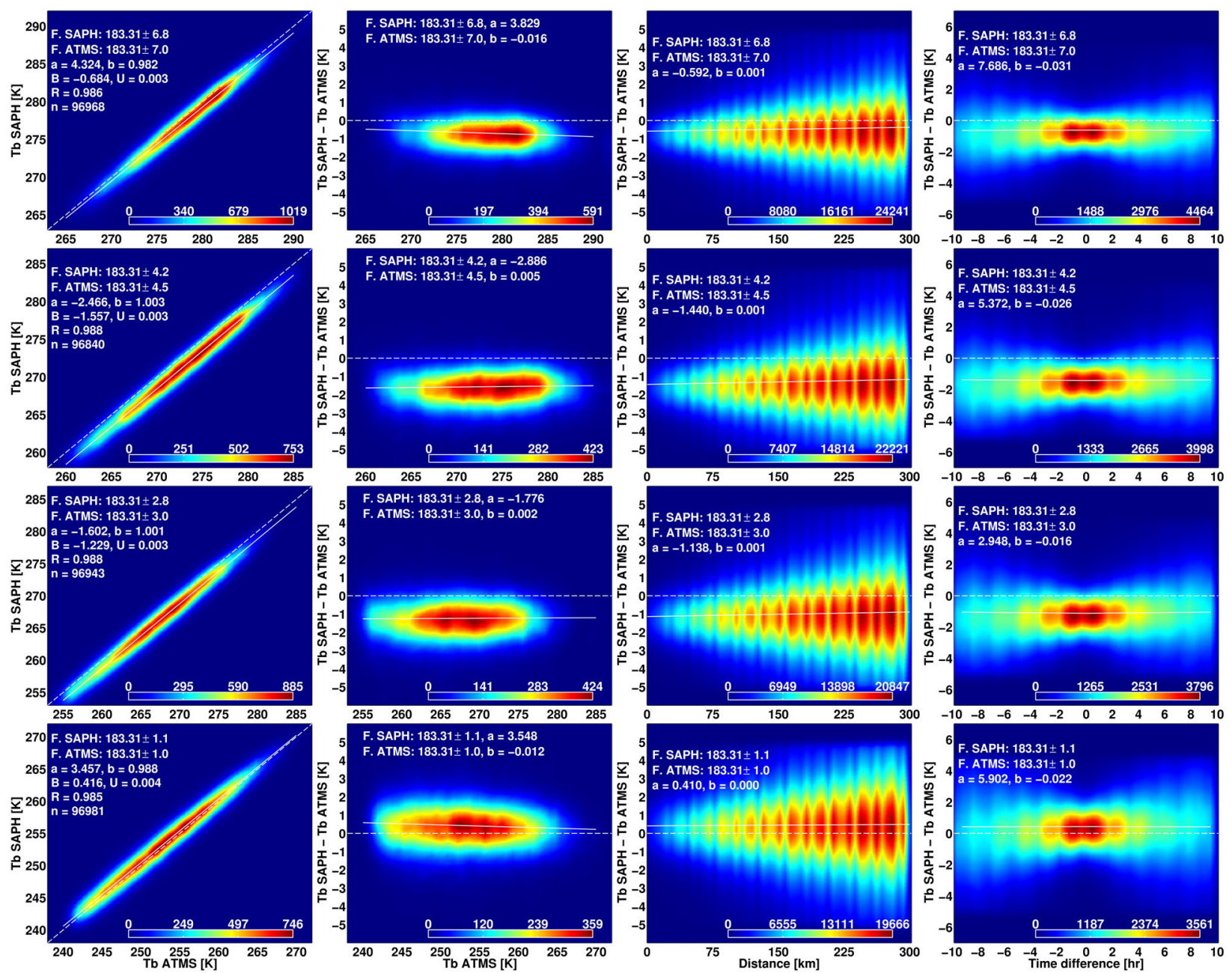

Fig. 3. Collocated SAPHIR and ATMS observations. Rows indicate results for different channels (frequencies of both ATMS and SAPHIR channels are printed on the plots). First column shows SAPHIR Tb's versus collocated ATMS Tb's, and second to fourth columns show the difference between SAPHIR and ATMS Tb's (SAPHIR minus ATMS) as a function of ATMS Tb (scene temperature), distance between collocated SAPHIR and ATMS data, and time difference between collocated SAPHIR and ATMS data, respectively. F indicates frequency of the channels, a and b indicate the offset and slope of the fitted line, B indicates the mean difference between SAPHIR and ATMS Tb's in Kelvin, $\mathrm{U}$ is uncertainty of the bias in Kelvin, $\mathrm{R}$ indicates the correlation coefficient, and $\mathrm{n}$ indicates number of collocations. 


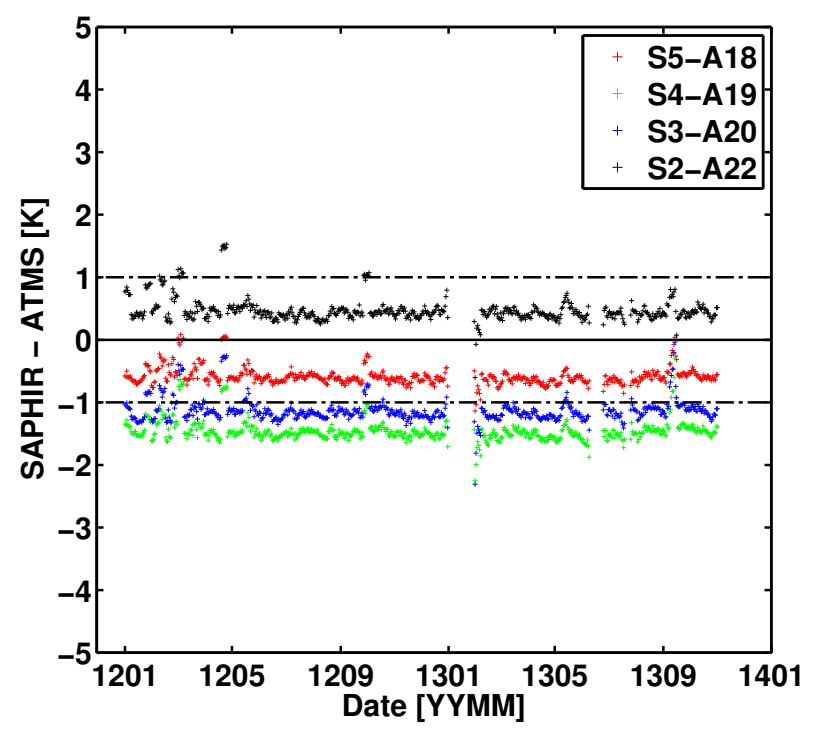

Fig. 4. Time series of the weakly moving averages of differences between SAPHIR and ATMS measurements. In the legend, $\mathrm{S}$ indicates the SAPHIR channel number and A indicates the corresponding ATMS channel. 

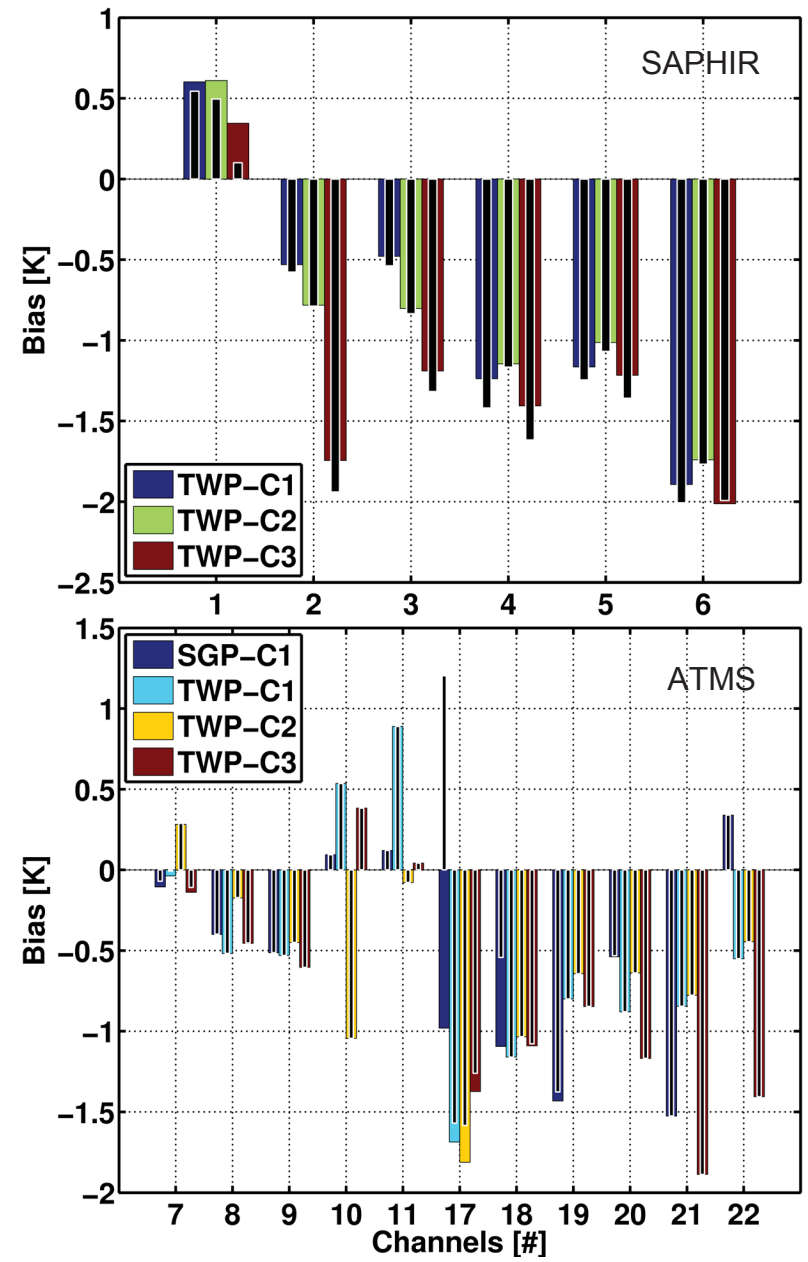

Fig. 5. Mean difference between SAPHIR/ATMS Tb's and Tb's simulated using ARM radiosonde profiles. The color-bars indicate the bias with respect to the ARM Tb's simulated using land emissivity and the black-bars indicate the bias with respect to the ARM Tb's simulated using ocean emissivity. Top panel is for SAPHIR channels where the x-labels 1-6 indicate SAPHIR S1 to S6 channels, respectively. Bottom panel is for ATMS where the x-labels show ATMS channels' number. 


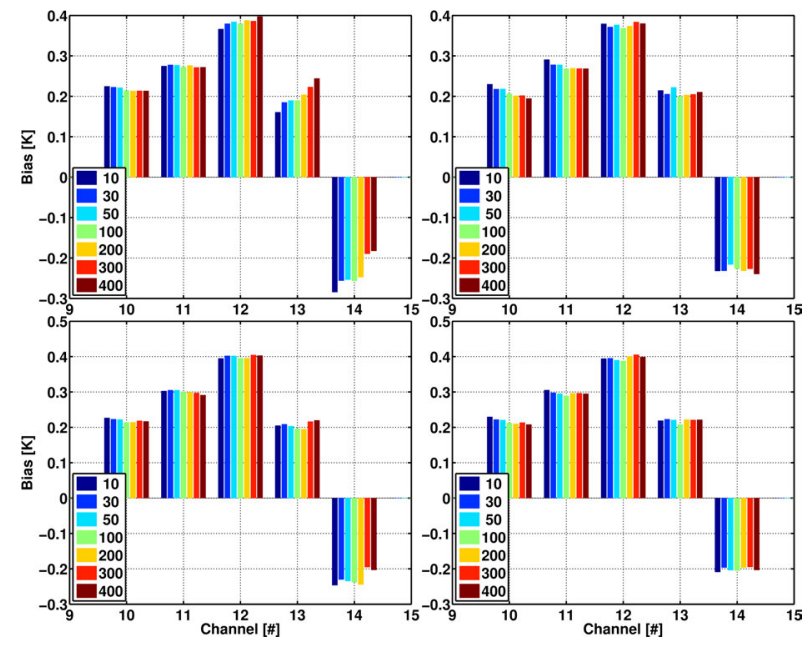

Fig. 6. Mean difference between ATMS and GPS-RO Tb's. The time difference threshold was 30 minutes for the first row and 60 minutes for the second row. The spatial distance threshold was $50 \mathrm{~km}$ for the first column and $100 \mathrm{~km}$ for the second column. The legend indicates the altitude (in $\mathrm{hPa}$ ) where GPS coordinates were used for collocation. 


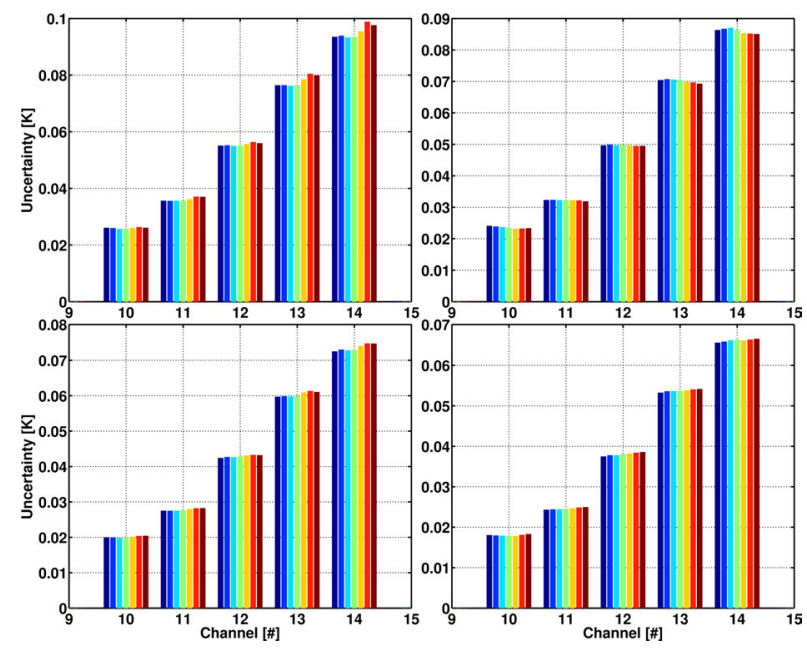

Fig. 7. Same as Figure 6 but for the statistical uncertainty of the mean difference between GPS-RO and ATMS. 


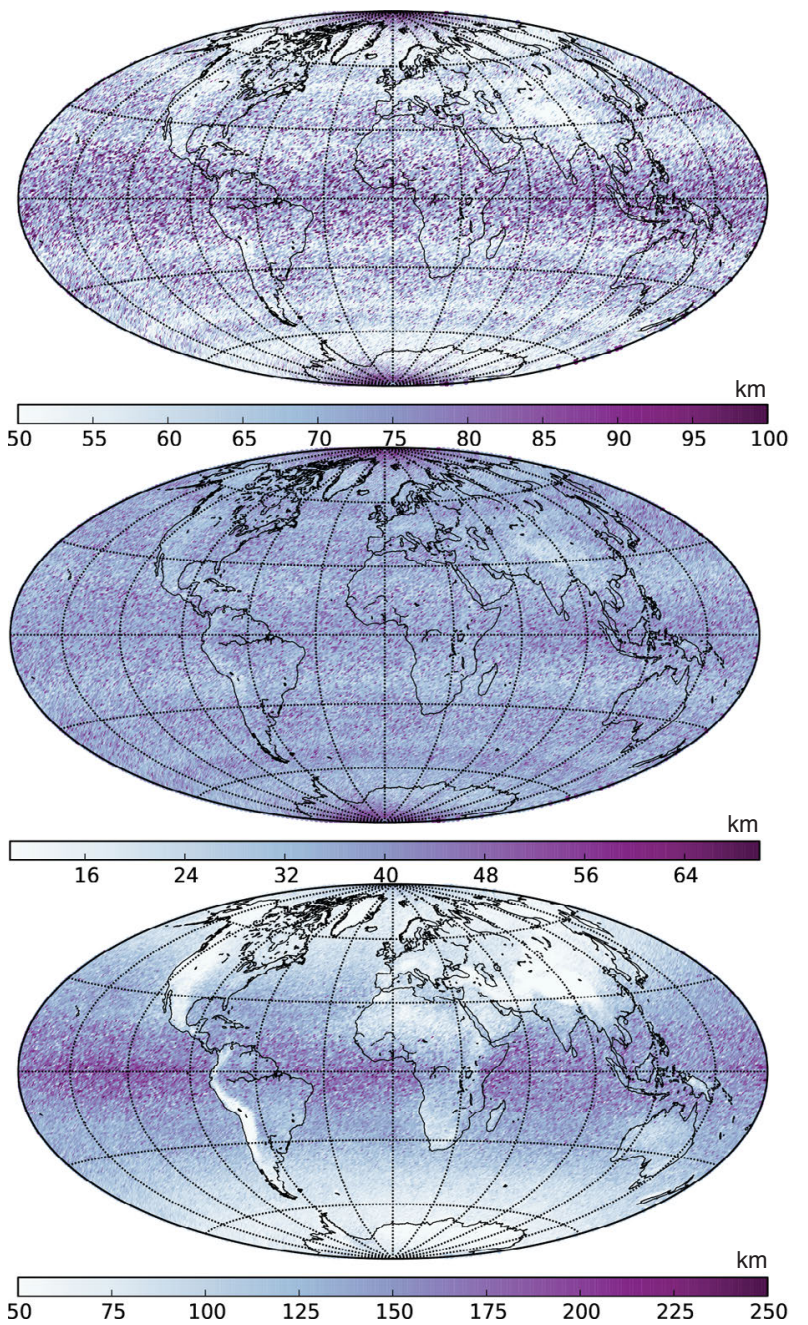

Fig. 8. Drift in GPS profiles at different altitudes: (top) drift from $400 \mathrm{hPa}$ to $10 \mathrm{hPa}$, (middle) drift from $400 \mathrm{hPa}$ to $100 \mathrm{hPa}$, and (bottom) drift from ground to $400 \mathrm{hPa}$. The legends show the drift in $\mathrm{km}$. 


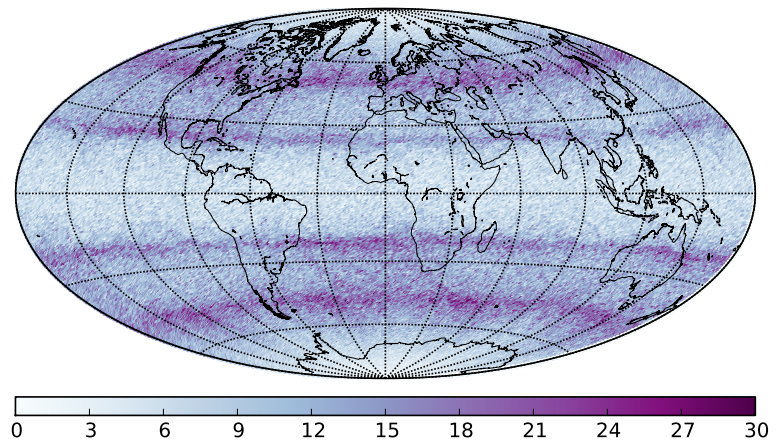

Fig. 9. Spatial distribution of the number of GPS-RO profiles. 

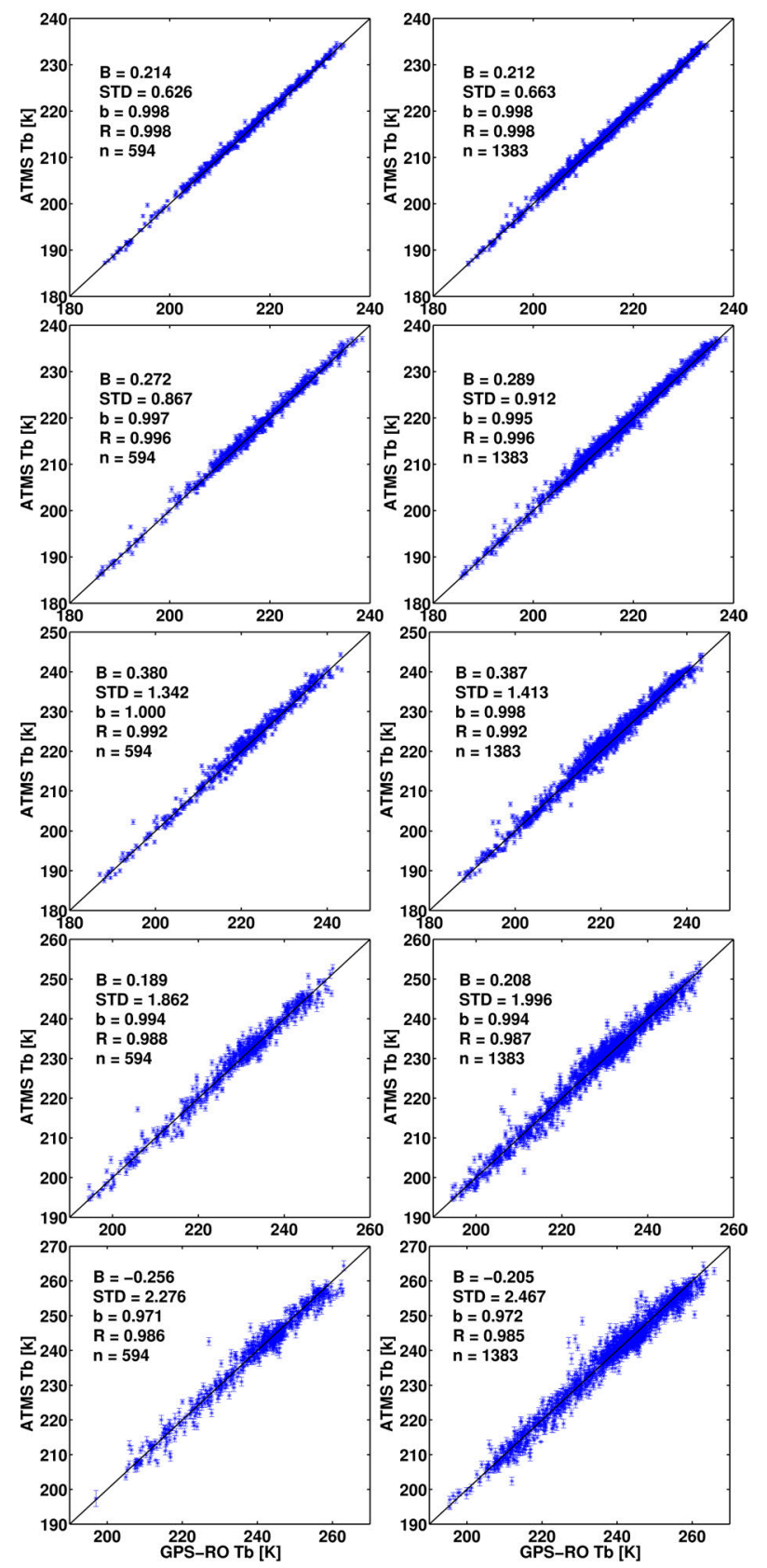

Fig. 10. ATMS Tb's versus Tb's simulated using GPS-RO profiles. The rows from top to bottom are for Channels 10-14. The temporal and spatial thresholds were $50 \mathrm{~km}$ and $30 \mathrm{~min}$ for the left column and $100 \mathrm{~km}$ and $60 \mathrm{~min}$ for the right column. B is bias in K, STD is standard deviation of the differences between simulated and observed Tb's, $b$ is the slope of the fitted line, $\mathrm{R}$ is correlation coefficient, and $\mathrm{n}$ is number of data points. 


\section{LIST OF TABLES}

I ATMS radiometric and channel characteristics. BDW is bandwidth in MHz, BMW is beamwidth in degrees, Ant indicates the antenna, frequency is in GHz, and $\mathrm{NE} \Delta \mathrm{T}$ is in Kelvin [15] . . . . . . 26

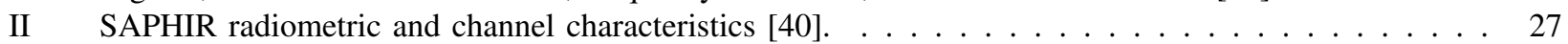

III Observed and simulated differences between ATMS, SAPHIR, and MHS measurements. $D_{O}$ and $D_{S}$ indicate SAPHIR minus ATMS observations and simulations, respectively. S-A indicates the double difference $\left(D_{O}-D_{S}\right)$ for SAPHIR and ATMS, S-M indicates the double difference for SAPHIR and MHS, and M-A is the difference between the MHS and ATMS instruments. . . . . . . . . . . 28 
TABLE I

ATMS RADIOMETRIC AND CHANNEL CHARACTERISTICS. BDW IS BANDWIDTH IN MHZ, BMW IS BEAMWIDTH IN DEGREES, ANT INDICATES THE ANTENNA, FREQUENCY IS IN GHZ, AND NE $\Delta$ T IS IN KELVIN [15]

\begin{tabular}{lllllll}
\hline Chan. & Frequency & BDW & NE $\Delta$ T & BMW & Pol. & Ant \\
\hline 1 & 23.80 & 270 & 0.5 & 5.2 & $\mathrm{~V}$ & $\mathrm{~A}$ \\
2 & 31.40 & 180 & 0.6 & 5.2 & $\mathrm{~V}$ & $\mathrm{~A}$ \\
3 & 50.30 & 180 & 0.7 & 2.2 & $\mathrm{H}$ & $\mathrm{A}$ \\
4 & 51.760 & 400 & 0.5 & 2.2 & $\mathrm{H}$ & $\mathrm{A}$ \\
5 & 52.80 & 400 & 0.5 & 2.2 & $\mathrm{H}$ & $\mathrm{A}$ \\
6 & $53.596 \pm 0.115$ & 170 & 0.5 & 2.2 & $\mathrm{H}$ & $\mathrm{A}$ \\
7 & 54.40 & 400 & 0.5 & 2.2 & $\mathrm{H}$ & $\mathrm{A}$ \\
8 & 54.94 & 400 & 0.5 & 2.2 & $\mathrm{H}$ & $\mathrm{A}$ \\
9 & 55.50 & 330 & 0.5 & 2.2 & $\mathrm{H}$ & $\mathrm{A}$ \\
10 & $57.290344[\mathrm{f} 0]$ & 330 & 0.75 & 2.2 & $\mathrm{H}$ & $\mathrm{A}$ \\
11 & $\mathrm{f} \pm \pm 0.217$ & 78 & 1.0 & 2.2 & $\mathrm{H}$ & $\mathrm{A}$ \\
12 & $\mathrm{f} 0 \pm 0.322 \pm 0.048$ & 36 & 1.0 & 2.2 & $\mathrm{H}$ & $\mathrm{A}$ \\
13 & $\mathrm{f} 0 \pm 0.322 \pm 0.022$ & 16 & 1.5 & 2.2 & $\mathrm{H}$ & $\mathrm{A}$ \\
14 & $\mathrm{f} 0 \pm 0.322 \pm 0.010$ & 8 & 2.2 & 2.2 & $\mathrm{H}$ & $\mathrm{A}$ \\
15 & $\mathrm{f} 0 \pm 0.322 \pm 0.0045$ & 3 & 3.6 & 2.2 & $\mathrm{H}$ & $\mathrm{A}$ \\
\hline 16 & 88.20 & 2000 & 0.3 & 2.2 & $\mathrm{~V}$ & $\mathrm{~B}$ \\
17 & 165.50 & 3000 & 0.6 & 1.1 & $\mathrm{H}$ & $\mathrm{B}$ \\
18 & $183.31 \pm 7.0$ & 2000 & 0.8 & 1.1 & $\mathrm{H}$ & $\mathrm{B}$ \\
19 & $183.31 \pm 4.5$ & 2000 & 0.8 & 1.1 & $\mathrm{H}$ & $\mathrm{B}$ \\
20 & $183.31 \pm 3.0$ & 1000 & 0.8 & 1.1 & $\mathrm{H}$ & $\mathrm{B}$ \\
21 & $183.31 \pm 1.8$ & 1000 & 0.8 & 1.1 & $\mathrm{H}$ & $\mathrm{B}$ \\
22 & $183.31 \pm 1.0$ & 500 & 0.9 & 1.1 & $\mathrm{H}$ & $\mathrm{B}$ \\
\hline
\end{tabular}


TABLE II

SAPHIR RADIOMETRIC AND CHANNEL CHARACTERISTICS [40].

\begin{tabular}{llll}
\hline Chan. & Frequency & Bandwidth & NEDT \\
\hline S1 & $183.31 \pm 0.20$ & 200 & 2.35 \\
S2 & $183.31 \pm 1.10$ & 350 & 1.45 \\
S3 & $183.31 \pm 2.80$ & 500 & 1.36 \\
S4 & $183.31 \pm 4.20$ & 700 & 1.38 \\
S5 & $183.31 \pm 6.80$ & 1200 & 1.03 \\
S6 & $183.31 \pm 11.0$ & 200 & 1.10 \\
\hline
\end{tabular}


TABLE III

OBSERVED AND SIMULATED DIFFERENCES BETWEEN ATMS, SAPHIR, AND MHS MEASUREMENTS. $D_{O}$ AND $D_{S}$ INDICATE SAPHIR MINUS ATMS OBSERVATIONS AND SIMULATIONS, RESPECTIVELY. S-A INDICATES THE DOUBLE DIFFERENCE $\left(D_{O}-D_{S}\right)$ FOR SAPHIR AND ATMS, S-M INDICATES THE DOUBLE DIFFERENCE FOR SAPHIR AND MHS, AND M-A IS THE DIFFERENCE BETWEEN THE MHS AND ATMS INSTRUMENTS.

\begin{tabular}{lllllll}
\hline ATMS & SAPHIR & $D_{o}$ & $D_{s}$ & S-A & S-M & M-A \\
\hline $183 \pm 7.0$ & $183 \pm 6.8$ & -0.68 & -0.42 & -0.26 & +0.20 & -0.46 \\
$183 \pm 4.5$ & $183 \pm 4.2$ & -1.56 & -0.91 & -0.65 & & \\
$183 \pm 3.0$ & $183 \pm 2.8$ & -1.23 & -0.93 & -0.30 & -0.45 & +0.15 \\
$183 \pm 1.0$ & $183 \pm 1.1$ & +0.42 & +0.90 & -0.48 & -0.09 & -0.39 \\
\hline
\end{tabular}

